\title{
Tetrandrine inhibits hepatocellular carcinoma cell growth through the caspase pathway and $G_{2} / M$ phase
}

\author{
VIVIAN W.L. YU and WING SHING HO \\ School of Life Sciences, The Chinese University of Hong Kong, Hong Kong, SAR, P.R. China
}

Received November 20, 2012; Accepted January 18, 2013

DOI: $10.3892 /$ or.2013.2352

\begin{abstract}
Activation of p53-independent pathways plays an important role in phytochemical-induced apoptosis and is considered to be a crucial factor in the invasion and metastasis of cancer. Previous studies have shown that combined effects of Stephania tetrandra with medicinal herbs exhibit beneficial effects in cancer patients. Tetrandrine, an active component of Stephania tetrandra has been reported to have anticancer properties in cancer cells. However, the mechanism(s) of action of tetrandrine in liver cancer have yet to be fully elucidated. In this study, we investigated the effects of tetrandrine in hepatocellular carcinoma (HCC) cells. The results showed that tetrandrine inhibited $\mathrm{HCC}$ cell proliferation by suppression of cell cycle progression at the $\mathrm{G}_{2} / \mathrm{M}$ phase. Changes in the expression levels of $\mathrm{Bax}, \mathrm{Bcl}$, p53, survivin, PCNA, PARP and p21 were observed. In addition, tetrandrine increased caspase- 3 expression and induced DNA fragmentation in Huh-7 cells. The results suggest that the anti-cancer effect of tetrandrine in Huh-7 cells may be mediated by $\mathrm{p} 53$-independent pathways.
\end{abstract}

\section{Introduction}

Hepatocellular carcinoma ( $\mathrm{HCC}$ ) is the most common form of liver cancer and is one of the leading causes of cancerrelated mortality worldwide (1). Invasion and metastasis of liver cancer contribute to treatment failure in the majority of cancer patients. Liver cancer is generally diagnosed at a later stage of cancer development. Liver metastasis and treatment are related to the characteristics of the tumor and the immune system of the host. Understanding the apoptotic pathways and their corresponding inhibitors enables us to formulate strategies for cancer therapy. The overexpression of genes that are associated with cell growth and programed cell death depend on the activity of the p53-associated pathways. During malig-

Correspondence to: Professor Wing Shing Ho, School of Life Sciences, The Chinese University of Hong Kong, Shatin, Hong Kong, SAR, P.R. China

E-mail:ws203ho@cuhk.edu.hk

Key words: tetrandrine, Huh-7, cancer, cell cycle, inhibition nant progression, the human papillomaviruses integrate into the liver cell genome resulting in a loss of expression of oncogenes. The gene proteins may lead to interference with the tumor suppression protein p53, which is activated in response to stress and plays an important role in the regulation of cell cycle, DNA repair and apoptosis (2). Genomic alterations of p53 can be found in cancer and deletion of p53 in cancer cells could lead to their resistance to apoptosis (2). Tumor suppressor p53 is involved in transcriptional activation of the human Bax gene $(3,4)$. Apoptosis-inducing factor plays a role in the regulation of caspase-independent cell death $(5,6)$. The most common risk factor for HCC is the hepatitis B (HBV) or hepatitis $\mathrm{C}$ viral (HCV) infection, of which there is a high incidence rate in China (1). Approximately one fourth of the carriers could develop liver cancer. An antiviral approach against human transcriptional inactivation of viral infection is used for HCV infection. Complementary medicine using herbal ingredients against transcriptional inactivation of cancer cells showed minimal system toxicity and could be a promising agent for liver cancer therapy particularly at an early stage of liver carcinogenesis. Cancer patients can have a higher survival rate with the complementary treatment. Tetrandrine is a bisbenzylisoquinoline alkaloid, a naturally occurring compound isolated from the root of Stephania tetrandra, which was reported to exhibit a variety of pharmacological properties including anti-inflammatory, anti-rheumatic and anti-hypertensive effects (7). It can inhibit the proliferation of HeLa and HepG2 cells in vitro and suppress ascites tumors in mice (8). Tetrandrine was reported to suppress $\mathrm{Wnt} / \beta$-catenin signaling and tumor growth of human colorectal cancer (9). A previous study showed that tetrandrine induced apoptosis by activating reactive oxygen species and repressing Akt activity in human liver cancer cells (10). The results suggest that mediation of the ROS/Akt pathway by tetrandrine can enhance the beneficial effects of tetrandrine in cells. Zhang et al showed that tetrandrine was used together with cisplatin to enhance growth suppression of ovarian cells and apoptosis (11). In vivo study of the combined effects of tetrandrine and cisplatin exhibited anticancer effects in the rat (11). The effect of tetrandrine with radiation on human esophageal cancer cell line TE1 showed that the expression of cyclin $B 1$ protein increased while radiation-induced $G_{2}$ arrest was abrogated (12). The study suggests that the enhanced cytotoxicity and activation of ROS-dependent caspase-3 activity could induce programmed cell death in cancer (13). 
Another study indicated that two distinct pathways could lead to the apoptosis of cancer cells (14). Apoptosis of cancer cells was considered to be associated with mitochondrial release of inducing factors that occurs downstream of cytochrome $c$ release in response to oxidative stress (15). A recent study showed that tetrandrine induced apoptosis via caspase cascade in human bladder cancer cells (16). Although tetrandrine was reported to have multiple biologic activities, the details of its anticancer properties are lacking. Therefore, we investigated the effect of tetrandrine on Huh-7 cancer cells.

\section{Materials and methods}

Cell culture and reagents. The human liver cell line Huh-7 was obtained from the American Type Culture Collection (USA) and cultured in DMEM (Gibco, USA) supplemented with RPMI and $0.25 \%$ trypsin-EDTA at $37^{\circ} \mathrm{C}$ in an atmosphere of $5 \% \mathrm{CO}_{2}-95 \%$ air. Tetrandrine was obtained from Sigma Chemicals (St. Louis, MO, USA).

In vitro cell viability assay. Cell proliferation was measured by a 3-(4,5-dimethylthiazol-2-yl)-2,5-diphenyl-tetrazolium bromide assay (MTT) according to the manufacturer's protocols. Huh-7 cells $\left(1 \times 10^{5}\right.$ cells/well) were placed in 96 -well microtiter plates (Corning) and incubated overnight. Cells were treated with either $1 \%$ serum DMEM as a control or with various concentrations of tetrandrine in 1\% DMEM for 24, 48 or $72 \mathrm{~h}$, respectively. At the end of the incubation period, $20 \mu \mathrm{l}$ of a $5-\mathrm{mg} / \mathrm{ml}$ solution of MTT prepared in PBS was placed into each well and the cells were incubated for an additional $4 \mathrm{~h}$. Cells were lysed in $200 \mu \mathrm{l}$ DMSO and absorbance was measured at $570 \mathrm{~nm}$. Six replicate wells were used for each analysis. The data represent the means \pm SD of three independent experiments with $95 \%$ confidence intervals.

Western blot analysis of gene expression. Western blotting assay was used to analyze the expressions of apoptotic proteins in Huh-7 cells. Cells $\left(1 \times 10^{6}\right)$ seeded in 6-well plates were exposed to various concentrations of tetrandrine for 24,48 and $72 \mathrm{~h}$. The cells were harvested and lysated ( $40 \mu \mathrm{g}$ of protein per lane) and fractionated by $10 \%$ SDS-PAGE as described below. The protein content was determined according to the Bradford method (17). Cells were collected in the 15-ml falcon and were re-suspended in $400 \mu 1$ of cell DNA lysis buffer in a $1.5-\mathrm{ml}$ microtube with vigorous mixing. Twenty microliters of $10 \mathrm{mg} / \mathrm{ml}$ proteinase $\mathrm{K}$ were added to each microtube. The mixtures were incubated at $37^{\circ} \mathrm{C}$ for $3 \mathrm{~h}$. Saturated $\mathrm{NaCl}$ solution $(50 \mu \mathrm{l})$ was added to each sample tube prior to centrifugation at 7,000 $\mathrm{x}$ g for $15 \mathrm{~min}$ at room temperature. The supernatant containing DNA was collected. Ice cold absolute ethanol $(1 \mathrm{ml})$ was added to the tubes with mixing followed by centrifugation at $14,000 \times \mathrm{g}$ at $4^{\circ} \mathrm{C}$ for $20 \mathrm{~min}$. The pellets were washed with $70 \%$ ethanol once. They were spun again at $14,000 \mathrm{x} \mathrm{g}$ at $4^{\circ} \mathrm{C}$ for $20 \mathrm{~min}$. The DNA pellet was allowed to air dry. TE buffer $(50 \mu \mathrm{l})$ containing $0.2 \mathrm{mg} / \mathrm{ml}$ of RNase A was added to the DNA pellets for RNA digestion prior to incubation at $37^{\circ} \mathrm{C}$ for $90 \mathrm{~min}$. DNA solution $(2 \mu \mathrm{l})$ from each sample was added to $998 \mu 1 \mathrm{TE}$ buffer. The concentrations of the DNA in the diluted solutions were measured by UV spectrophotometry (Beckman, DU 650) at $260 \mathrm{~nm}$.
Table I. The annealing and extension temperature used for different target genes.

\begin{tabular}{lc} 
Target gene & Annealing and extension temperature $\left({ }^{\circ} \mathrm{C}\right)$ \\
\hline Bax & 60 \\
Bid & 60 \\
Bcl-2 & 55 \\
GAPDH & 60 \\
p21 & 65 \\
Survivin & 60 \\
\hline
\end{tabular}

Gel electrophoresis of DNA. Agarose $(0.3 \mathrm{~g})$ was added to $20 \mathrm{ml}$ TBE buffer. Ethidium bromide $(2 \mu \mathrm{l})$ was added to the agarose solution followed by the addition of $10 \mu \mathrm{l}$ of the dissolved DNA samples and $2 \mu 16 \mathrm{X}$ DNA loading dye. The mixtures were loaded on the $1.5 \%$ agarose gel and it was run at $75 \mathrm{~V}$ for $1 \mathrm{~h}$. The DNA bands were visualized under UV illuminator. The gel was photographed for documentation.

Measurement of gene expression in tetrandrine-induced cancer cells. Huh-7 cells $\left(1 \times 10^{6}\right)$ were seeded on 6-well plates with different concentrations of tetrandrine $(0,7.5,15$ and $20 \mu \mathrm{M})$. After $24 \mathrm{~h}$ of incubation, cells were harvested by trypsinization and washed with $1 \mathrm{X}$ PBS. The cell platelets were collected by centrifugation at $600 \mathrm{~g}$ for $2 \mathrm{~min}$ followed by the addition of $1 \mathrm{ml}$ TRIzol reagent. The mixtures were then incubated at room temperature for $5 \mathrm{~min}$ prior to the addition of $266 \mu \mathrm{l}$ chloroform. Subsequently, the samples were centrifuged at $14,000 \mathrm{rpm}$ for $15 \mathrm{~min}$. The supernatant was mixed with $70 \%$ ethanol in 1:1 volume ratio. RNeasy Mini kit ${ }^{\mathrm{TM}}$ from Qiagen was used for the total RNA extraction. The mRNA extraction was conducted according to the manufacturer's method. The total RNA concentration of each sample assay was measured. The same amount of total RNA was used in each sample for cDNA synthesis. Transcriptor First Strand cDNA Synthesis kit from Roche was used for cDNA synthesis.

Reverse-transcription-PCR (RT-PCR) and detection of gene products. Each RT-PCR reaction mixture contained $11.2 \mu \mathrm{l}$ water, $4 \mu \mathrm{l} 5 \mathrm{X}$ Green GoTaq Flexi Buffer, $1.2 \mu \mathrm{I} \mathrm{MgCl}_{2}$ (25 mM), $1 \mu 1$ primer, $0.4 \mu \mathrm{ldNTP}, 0.2 \mu \mathrm{l} \mathrm{GoTaq}{ }^{\circledR}$ Hot Start Polymerase $5 \mathrm{U} / \mu \mathrm{l}, 2 \mu \mathrm{l}$ cDNA template. The reaction was conducted at $95^{\circ} \mathrm{C}$ for $5 \mathrm{~min}$ and the denaturation was at $95^{\circ} \mathrm{C}$ for $30 \mathrm{sec}$. Annealing and extension were performed in one step over $1 \mathrm{~min}$ (Table I). The PCR products were detected by running a $2 \%$ agarose gel. Agarose $(0.4 \mathrm{~g})$ was dissolved in $20 \mathrm{ml} 1 \mathrm{X}$ TBE buffer. The $2 \%$ agarose gel was run at $100 \mathrm{~V}$ for $30 \mathrm{~min}$ to separate the PCR products.

Measurement of protein expression in tetrandrine-induced apoptotic cells. Huh-7 cells $\left(1 \times 10^{6}\right)$ were seeded into a $100-\mathrm{mm}$ dish with different concentrations of tetrandrine for $24 \mathrm{~h}$ before being trypsinized and collected by centrifugation. The number of cells collected in each sample was counted using a hemocytometer. Whole cells lysis buffer $(200 \mu \mathrm{l})$ was 
added per $1 \times 10^{6}$ cells and incubated at $37^{\circ} \mathrm{C}$ for $30 \mathrm{~min}$. The samples were then placed in boiling water for $10 \mathrm{~min}$ prior to centrifugation at $14,000 \mathrm{x}$ g for $15 \mathrm{~min}$. The supernatant of the samples was collected in a new micro-centrifuge tube for the protein concentration determination (17).

Protein gel electrophoresis by SDS-PAGE. Mini-PROTEAN ${ }^{\circledR}$ III cell with a 10-tooth comb from Bio-Rad was used for SDS-PAGE according to a previous method with modifications (17). A small quantity of isopropanol was layered on the top of the running gel solution before the excess isopropanol was discarded and $\mathrm{dH}_{2} \mathrm{O}$ was used to wash the gel. Stacking gel solution (4\%) was added onto the top of the running gel. The gel was allowed to stand until it polymerized. Sample loading dye $(2 \mathrm{X})$ was added to the protein samples in a 1:1 ratio prior to boiling at $100^{\circ} \mathrm{C}$ for $10 \mathrm{~min}$. Samples were loaded onto the wells and $1.5 \mu \mathrm{l}$ of PageRuler ${ }^{\mathrm{TM}}$ Prestained Protein Ladder was added as a protein marker. The gel was allowed to run at constant voltage. Fifty $\mathrm{V}$ were used for running the stacking gel whereas 80,100 and $120 \mathrm{~V}$ were used for running 10, 12 and $15 \%$ running gel, respectively. The SDS-PAGE was stopped after the dye front containing bromophenol blue reached the bottom of the gel.

Western blot analysis. Bio-Rad Semi-dry Trans-Blot electroblotter was used to transfer the protein onto the membrane according to the manufacturer's protocols. The gel was immersed into transfer buffer for $15 \mathrm{~min}$ for equilibration. The PVDF membrane was activated using $100 \%$ methanol and was washed twice using $\mathrm{dH}_{2} \mathrm{O}$ to remove methanol prior to equilibration in the transfer buffer for $15 \mathrm{~min}$. The running gel was placed above the membrane with another 3 pieces of paper. Constant current (0.1A) was used to transfer proteins for $2 \mathrm{~h}$. The PVDF membrane was rinsed with TBST buffer twice. The desired dilution of antibody was added to the suitable percentage of non-fat milk solution which was the same as that used in blocking. The membrane was finally blotted with different antibodies overnight at $4^{\circ} \mathrm{C}$. The membrane was washed with $1 \mathrm{X}$ TBST containing $0.2 \%$ Tween-20 three times, 15 min each. After washing, the membrane was blotted with the corresponding secondary antibody. The dilution for anti-mouse and anti-rabbit were 1:10,000 and 1:6,667, respectively. The secondary antibodies were diluted in non-fat milk solution. The blocking solution contained the same concentration of non-fat milk as that for the primary antibody. The membrane was agitated for $1 \mathrm{~h}$ at room temperature. After probing with secondary antibody, the membrane was washed with $1 \mathrm{X}$ TBST containing $0.1 \%$ Tween-20 solution three times, each with $10 \mathrm{~min}$.

Rodeo $^{\mathrm{TM}}$ ECL Western Blotting Reagents from USB Biochemicals was used for the signal development. The two reagents in the kit were mixed in a 1:1 ratio. The mixture was equilibrated at room temperature for $5 \mathrm{~min}$ prior to use. Excess TBST solution on the membrane was removed by blotting it onto the M-fold tissue paper. The western blotting reagent mixture was added slowly onto the membrane with the size mobilized with proteins faced upward. Protein bands on the membrane were visualized after exposing to Fuji Super RX film. The intensities of the bands were analyzed using ImageJ program.

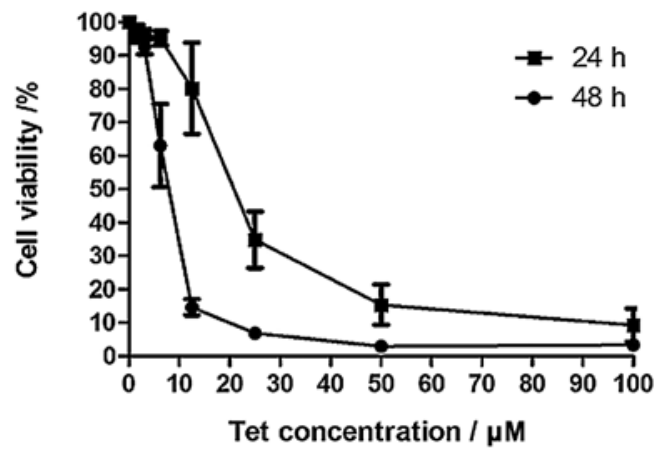

Figure 1. Huh-7 cells were seeded in 96-well microplates and were incubated with different concentrations of tetrandrine for 24 and $48 \mathrm{~h}$. The viability of the cells was measured by MTT assay using DMSO as blank. The values are the means of three individual experiments. The data represent the means $\pm \mathrm{SD}$ $(n=3)$.

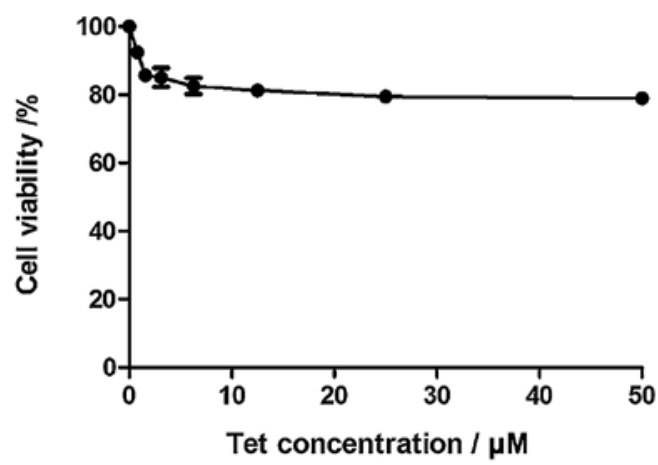

Figure 2. WRL68 cells were seeded in 96-well microplates and were incubated with different concentrations of tetrandrine for $24 \mathrm{~h}$. The viability of the cells was measured by MTT assay using DMSO as blank. The values are the means of three individual experiments. The data represent the means $\pm \operatorname{SD}(n=3)$.

Cell cycle analysis of tetrandrine-treated cells. Huh-7 cells $\left(1 \times 10^{6}\right)$ were seed into a $100-\mathrm{mm}$ dish with different concentrations of tetrandrine for 24, 24 and $72 \mathrm{~h}$. The tetrandrine-treated Huh-7 cells were trypsinized and were collected in a $15-\mathrm{ml}$ falcon prior to centrifugation at 3,000 x g for $3 \mathrm{~min}$. The cells were re-suspended in $1 \mathrm{ml} 1 \mathrm{X}$ PBS prior to centrifugation at $3,000 \mathrm{x} \mathrm{g}$ for $3 \mathrm{~min}$. The cells were collected by centrifugation in sequence after washing in $2 \mathrm{ml}$ of $70 \%$ ethanol, RNase containing PBS solution, $1 \mathrm{ml}$ propidium iodide solution. The cells in $1 \mathrm{ml}$ propidium iodide solution were centrifuged at $3,000 \times \mathrm{g}$ for $3 \mathrm{~min}$ prior to flow cytometry analysis. The DNA content of the treated cells was recorded and analyzed by FACSCanto flow cytometer.

Statistical analysis. Statistical analysis was conducted using ANOVA. All experiments were performed three times independently. Data are expressed as the means \pm SD.

\section{Results}

Fig. 1 shows the cell viability of Huh-7 cells following treatment with different concentrations of tetrandrine for 24 and $48 \mathrm{~h}$. The viability of cells significantly decreased when tetrandrine concentration was increased. The $\mathrm{IC}_{50}$ of cells after 24 and $48 \mathrm{~h}$ of incubation were found to be 20.8 and $8.0 \mu \mathrm{M}$, 


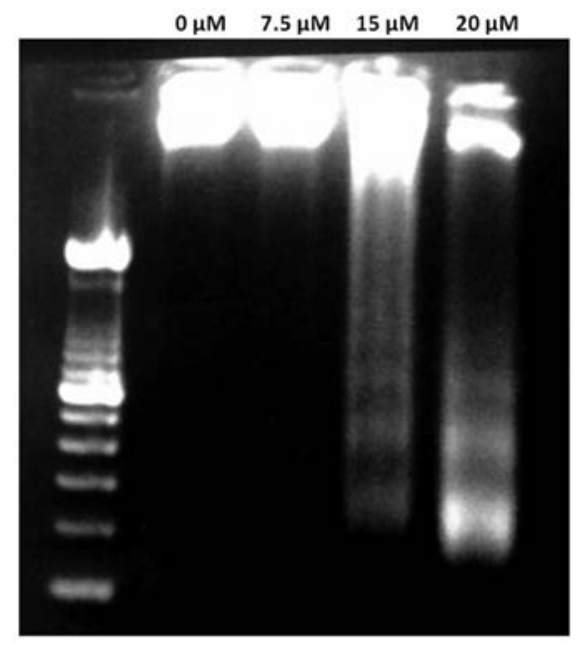

Figure 3. Huh-7 cells were incubated with $0,7.5,15$ and $20 \mu \mathrm{M}$ tetrandrine for $24 \mathrm{~h}$. DNA contents extracted were analyzed by agarose gel electrophoresis with $2 \%$ agarose gel. The DNA ladders were visualized using UV illuminator after staining with ethidium bromide.
A

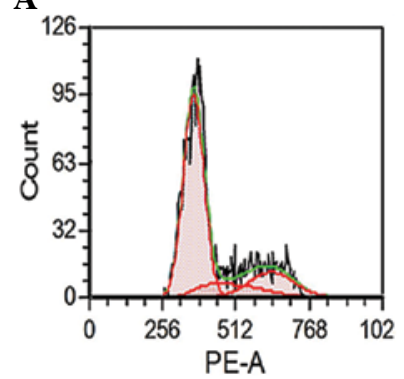

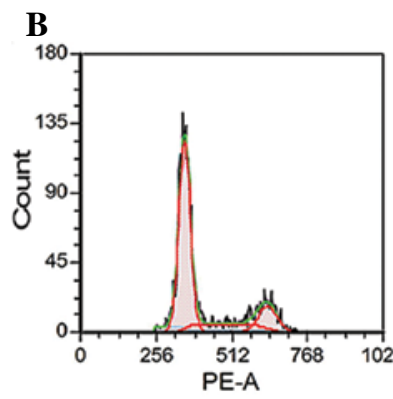

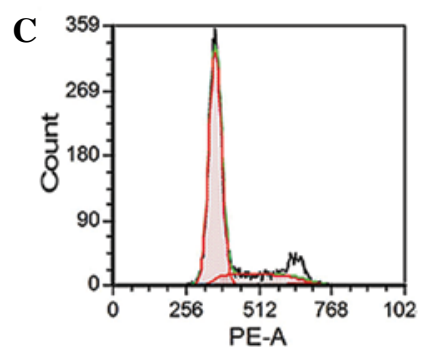

Figure 4. Flow cytometry analysis of Huh-7 cells treated with tetrandrine for $24 \mathrm{~h}$. Huh-7 cells were incubated with (A) $0 \mu \mathrm{M}$, (B) $5 \mu \mathrm{M}$ and (C) $10 \mu \mathrm{M}$ of tetrandrine for $24 \mathrm{~h}$. The DNA contents of the cells were evaluated by propidium iodide staining. Data represent the means of three individual sets of experiments.

respectively. After $48 \mathrm{~h}$ of incubation, the cell viability was reduced. Fig. 2 shows the effect the tetrandrine on WRL68 cells. The cell viability of WRL68 cells decreased when tetrandrine concentration increased, but leveled off when its concentration reached $3.125 \mu \mathrm{M}$. No $\mathrm{IC}_{50}$ for WRL68 could be determined. Fig. 3 shows the DNA fragmentation of tetrandrine-treated Huh-7 cells. DNA ladders were observed in the tetrandrine-treated samples but not in the control. Fig. 4 shows the flow cytometry analysis of Huh-7 cells after treatment with tetrandrine for $24 \mathrm{~h}$. The similar pattern of results of flow cytometry after 48 and $72 \mathrm{~h}$ of incubation of cells was recorded. The results are summarized in Fig. 5 and indicate
A

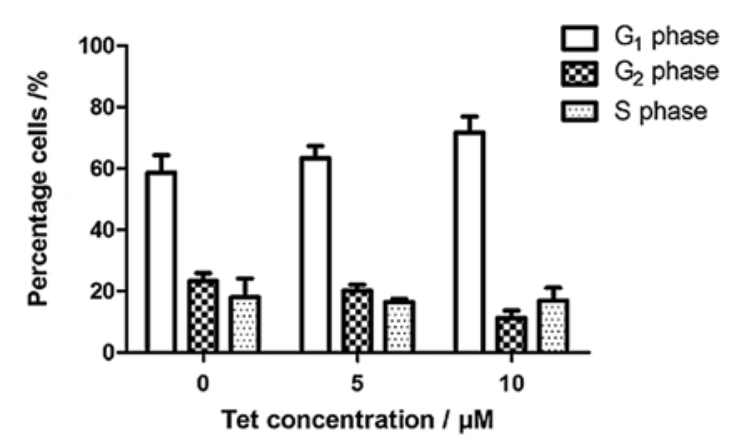

$\mathbf{B}$

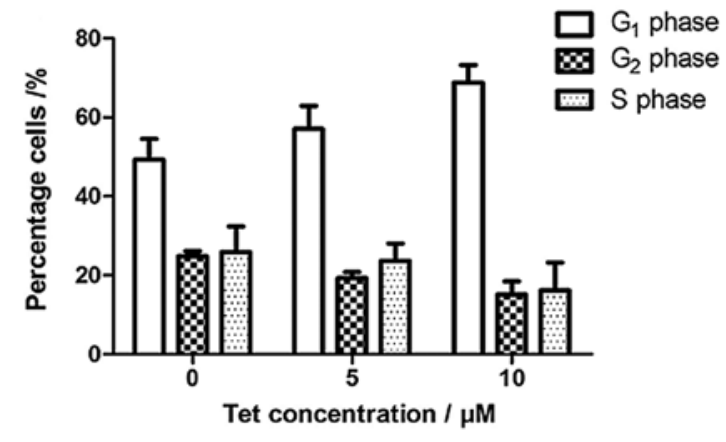

C

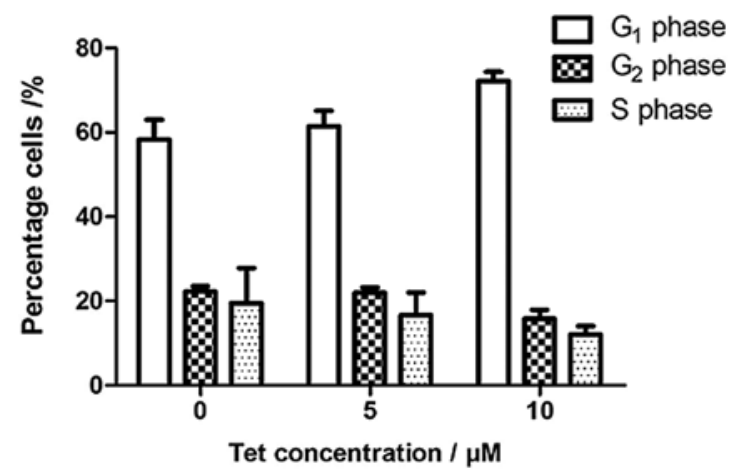

Figure 5. The graphs show the cell cycle analysis (\%) of Huh-7 cells after (A) 24 , (B) 48 and (C) $72 \mathrm{~h}$ of treatment with 0,5 and $10 \mu \mathrm{M}$ of tetrandrine. The data represent the means $\pm \mathrm{SD}(\mathrm{n}=3)$.

the distribution of the cell populations in $G_{1}, S$ and $G_{2}$ phase following treatment with tetrandrine. The cell percentage in each phase of the cell cycle was analyzed by FACS Express. The cell population in the $\mathrm{G}_{1}$ phase increased from 58.63 to $71.72 \%$ after $24 \mathrm{~h}$, from 49.30 to $68.74 \%$ after $48 \mathrm{~h}$ and from 58.30 to $72.15 \%$ after $72 \mathrm{~h}$ of treatment. For the cell population within the $\mathrm{S}$ phase, the percentages decreased slightly from 18.07 to $16.95 \%$ for $24 \mathrm{~h}$, from 25.88 to $16.14 \%$ for $48 \mathrm{~h}$ and from 19.47 to $12.09 \%$ for $72 \mathrm{~h}$ of incubation. The cell population within the $\mathrm{G}_{2}$ phase decreased at all the time points. It decreased from 2.30 to $11.33 \%$, from 24.83 to $15.14 \%$ and from 22.24 to $15.76 \%$ for 24,48 and $72 \mathrm{~h}$ of incubation, respectively. Fig. 6 shows the mRNA expression of survivin, Bax, Bid and p21 in tetrandrine-treated cancer cells. The expression levels of these genes were evaluated by the RT-PCR. Fig. 7 shows the western blots of different apoptotic proteins after Huh-7 cells were treated with tetrandrine. When the tetrandrine concentration was increased from 0 to $20 \mu \mathrm{M}$, the band intensities for the full-length PARP, pro-caspase-9, PCNA and Bcl-2 were found to be decreased while the intensities for bands of cleaved PARP, 


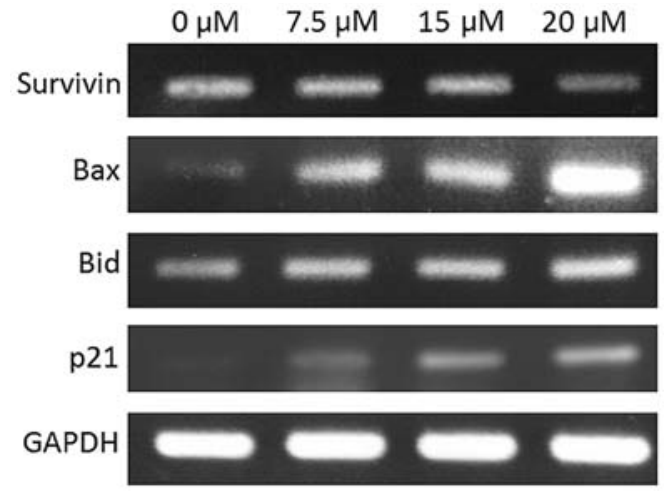

Figure 6. Huh-7 cells were treated with $0,7.5,15$ and $20 \mu \mathrm{M}$ tetrandrine for $24 \mathrm{~h}$. The mRNA of lysed cells was extracted and was converted to cDNA. The gene expression levels of Bax, Bid, p21 and survivin were evaluated by reverse-transcription PCR. GAPDH was used as the control. Data represent the means of three individual sets of experiments.

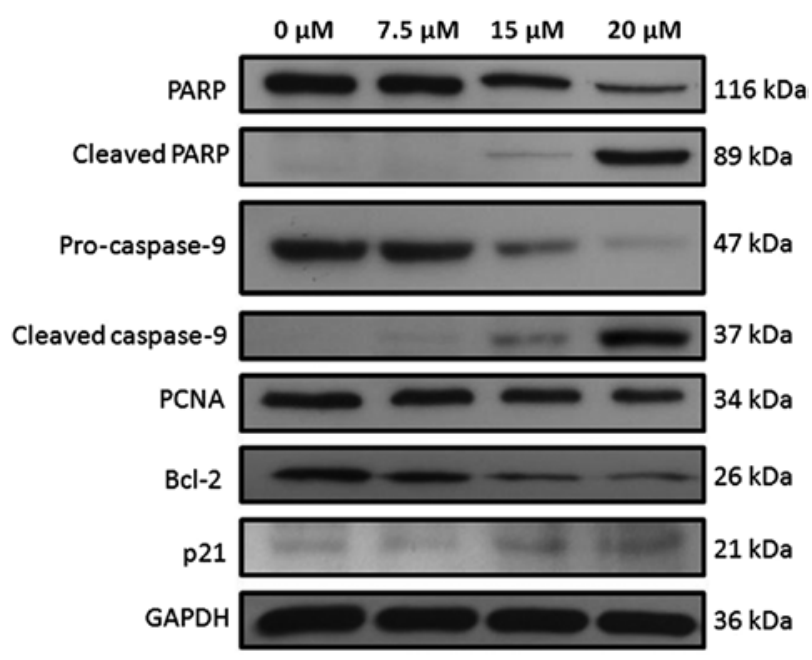

Figure 7. Huh-7 cells were treated with $0,7.5,15$ and $20 \mu \mathrm{M}$ of tetrandrine for $24 \mathrm{~h}$. Equal amounts of cell lysates $(60 \mu \mathrm{g})$ were subjected to electrophoresis. The levels of PARP, cleaved PARP, pro-caspase-9, cleaved caspase-9, PCNA, Bcl-2 and p21 were analyzed by western blotting. To ensure equal loading, the same blot was stripped and re-probed with anti-GAPDH which was used as the loading control. The results show the representative western blots from three individual experiments.

cleaved caspase- 9 and p 21 were found to be increased with the increased tetrandrine concentration. To ensure even loading of the total proteins, the blots were stripped and re-probed with anti-GAPDH. GAPDH was used as the control.

\section{Discussion}

The cell viability of Huh-7 decreased in a dose-dependent manner but remained almost unchanged in WRL68, the normal liver cells. The $\mathrm{IC}_{50}$ decreased from 20.8 to $8.0 \mu \mathrm{M}$ for Huh-7 cells with time. The low value of $\mathrm{IC}_{50}$ suggests that tetrandrine is a considerable candidate as an anticancer agent. The viability of WRL68 cells dropped and leveled off approximately $80.0 \%$ at $50 \mu \mathrm{M}$. No $\mathrm{IC}_{50}$ for WRL68 could be determined from the MTT assay. The results suggest tetrandrine is one of the few phytochemicals that can differentially act against cancer cell viability.
Cell death of Huh-7 cells induced by tetrandrine is mediated through apoptosis. The results from the DNA fragmentation assay clearly indicated that DNA ladders were detected in the tetrandrine-treated Huh-7 cells. The results provide supporting evidence that tetrandrine induces apoptosis of Huh-7 cells with increased concentration of tetrandrine. It suggests that more genomic DNA molecules were cleaved to form smaller DNA fragments at a higher tetrandrine concentration. The Huh-7 cell line is a p53 gene mutated cell line. In the absence of the functional p53 protein, apoptosis can still occur in Huh-7 cells suggesting that apoptosis does not require the activation of the p53 gene. The results suggest that tetrandrine could induce apoptosis through the p53-independent pathway.

Tetrandrine induces $G_{1}$ phase cell cycle arrest. Studies show that there is a link between cell proliferation and apoptosis of Huh-7. The results of the cell cycle analysis by flow cytometry showed that the percentage of cells in the $S$ and $G_{2}$ phases decreased whereas $G_{1}$ phase increased with increasing concentrations of tetrandrine at all the time points. It suggests that tetrandrine inhibits cell proliferation at a very early stage within the cell cycle. Tetrandrine induced programmed cell death via mediation of p21 and PCNA gene expression possibly through binding of p21 to cyclin-CDK 2 or -CDK 4 complexes and subsequently inhibits their activities. p21 plays an important role in cell cycle regulation by controlling the cell cycle progression from $G_{1}$ to $S$ phase. PCNA is synthesized in the early $G_{1}$ and $S$ phases during the cell cycle. It acts as an auxiliary factor for DNA polymerase $\delta$ in DNA synthesis during the $\mathrm{S}$ phase of the cell cycle. It is an important protein responsible for the regulation of DNA synthesis. The binding of p21 to PCNA inhibits the role of PCNA during DNA replication. Therefore, the decreased protein expression for PCNA indicates that there were fewer cells entering $S$ phase after treatment with tetrandrine. The results showed that a higher inhibitory effect on Huh-7 cells was observed in proceeding from $G_{1}$ to $S$ phase with higher concentrations of tetrandrine. Therefore, there were fewer proliferating cells and a larger population of cells was retained in $\mathrm{G}_{1}$ phase after treatment. The data from RT-PCR and western blot analysis also support the notion that tetrandrine induces $\mathrm{G}_{1}$ phase cell cycle arrest.

Tetrandrine-induced apoptosis involves the intrinsic, caspase-dependent pathway. Caspases are involved in both the initiation and execution of the programmed cell death. Western blot analysis showed that tetrandrine induced apoptosis of Huh-7 through caspase activity. The result showed that the protein expression for pro-caspase-9 decreased in a concentration-dependent manner. Furthermore, the expression for the cleaved, active caspase- 9 was found to be similarly increased. As caspase-9 is the initiator for the intrinsic apoptotic pathway, the cleavage of pro-caspase- 9 to form the active caspase- 9 is essential for inducing cell death in tetrandrine-treated Huh-7 cells and the intrinsic apoptotic pathway is involved.

In the intrinsic apoptotic pathway, the caspase cascade involves active caspase- 9 and pro-caspase-3. Following treatment of Huh-7 cells with tetrandrine, the protein expression for full-length PARP decreased in Huh-7 cells. The amount of cleaved PARP increased. PARP, an important protein for DNA repair, is the molecular substrate of active caspase-3. 
The occurrence of PARP cleavage is associated with DNA fragmentation in cells resulting in cell death. The result is concordant with the DNA integrity analysis for Huh-7 cells shown in Fig. 3. In the gene expression analysis in Huh-7 cells (Fig. 6), survivin expression was found to be decreased in a concentration-dependent manner. It is reported that survivin is an anti-apoptotic protein that exerts its function by binding to caspase- 3 and hence the caspase- 3 activity is suppressed. The decreased gene expression suggests that tetrandrine could promote apoptosis by suppressing the expression of survivin.

Tetrandrine induces expression of proteins in Bcl-2. The proteins in the Bcl-2 family can be classified into two categories, the pro-apoptotic and anti-apoptotic proteins. These proteins are involved in the apoptotic pathway associated with mitochondrial control. The gene expressions of Bax and Bid increased. Both the Bax and Bid are pro-apoptotic proteins whereas Bcl-2 is an anti-apoptotic protein. The pro- and antiapoptotic proteins exert their function in opposite ways. It is reported that $\mathrm{Bcl}-2$ was overexpressed whereas the expression of Bax was downregulated in HCC (4). The elevated gene expressions of Bax and Bid, and the suppressed gene expression of $\mathrm{Bcl}-2$, suggest that these proteins were involved in the apoptosis of Huh-7 cells.

\section{Acknowledgements}

This study was supported by grants from the Luck Tissue Mfy Ltd. We thank Matt Cheung for his technical assistance.

\section{References}

1. Jemal A, Bray F, Center MM, Ferlay J, Ward E and Forman D: Global cancer statistics. CA Cancer J Clin 61: 69-90, 2011.

2. Schuler M, Bossy-Wetzel E, Goldstein JC, Fitzgerald P and Green DR: p53 induces apoptosis by caspase activation through mitochondrial cytochrome c release. J Biol Chem 275: 7337-7342, 2000.

3. Chipuk JE, Maurer U, Green DR and Schuler M: Pharmacologic activation of p53 elicits Bax-dependent apoptosis in the absence of transcription. Cancer Cell 4: 371-381, 2003.

4. Oda E, Ohki R, Murasawa H, Nemoto J, Shibue T, Yamashita T, Tokino T, Taniguchi T and Tanaka N: Noxa, a BH 3-only member of the Bcl-2 family and candidate mediator of p53-induced apoptosis. Science 288: 1053-1058, 2000.
5. Cregan SP, Fortin A, MacLaurin JG, Callaghan SM, Cecconi F, Yu SW, Dawson TM, Dawson VL, Park DS and Kroemer G: Apoptosis-inducing factor is involved in the regulation of caspase-independent cell death. J Cell Biol 158: 507-517, 2002.

6. Miyashita T and Reed JC: Tumor suppressor p53 is a direct transcriptional activator of the human bax gene. Cell 80: 293-299, 1995.

7. Ng LT, Chiang LC, Lin YT and Lin CC: Antiproliferative and apoptotic effects of tetrandrine on different human hepatoma cell lines. Am J Chin Med 34: 125-135, 2006.

8. Yoo SM, Oh SH, Lee SJ, Lee BW, Ko WG, Moon CK and Lee BH: Inhibition of proliferation and induction of apoptosis by tetrandrine in HepG2 cells. J Ethnopharmacol 81: 225-229, 2002.

9. He BC, Gao JL, Zhang BQ, Luo Q, Shi Q, Kim SH, Huang E, Gao Y, Yang K, Wagner ER, Wang L, Tang N, Luo J, Liu X, Li M, Bi Y, Shen J, Luther G, Hu N, Zhou Q, Luu HH, Haydon RC, Zhao Y and He TC: Tetrandrine inhibits Wnt/ $\beta$-catenin signaling and suppresses tumor growth of human colorectal cancer. Mol Pharmacol 79: 211-219, 2011.

10. Liu C, Gong K, Mao X and Li W: Tetrandrine induces apoptosis by activating reactive oxygen species and repressing Akt activity in human hepatocellular carcinoma. Int J Cancer 129: 1519-1531, 2011.

11. Zhang Y, Wang C, Wang H, Wang K, Du Y and Zhang J: Combination of Tetrandrine with cisplatin enhances cytotoxicity through growth suppression and apoptosis in ovarian cancer in vitro and in vivo. Cancer Lett 304: 21-32, 2011.

12. Yu J, Liu F, Sun M, Sun Z and Sun S: Enhancement of radiosensitivity and the potential mechanism on human esophageal carcinoma cells by tetrandrine. Cancer Biother Radiopharm 26: 437-442, 2011.

13. Li X, Zhen D, Lu X, Xu H, Shao Y, Xue Q, Hu Y, Liu B and Sun W: Enhanced cytotoxicity and activation of ROS-dependent c-Jun $\mathrm{NH}_{2}$-terminal kinase and caspase-3 by low doses of tetrandrine-loaded nanoparticles in Lovo cells: a possible Trojan strategy against cancer. Eur J Pharm Biopharm 75: 334-340, 2010.

14. Arnoult D, Parone P, Mattinou JC, Antonsson B, Estaquier J and Ameisen JC: Mitochondrial release of apoptosis-inducing factor occurs downstream of cytochrome c release in reponse to several proapoptotic stimuli. J Cell Biol 159: 923-929, 2002.

15. Susin SA, Daugas E and Ravagnan L: Two distinct pathways leading to nuclear apoptosis. J Exp Med 192: 571-580, 2000.

16. Li X, Su B, Liu R, Wu D and He D: Tetrandrine induces apoptosis and triggers caspase cascade in human bladder cancer cells. J Sur Res 166: e45-51, 2011.

17. Laemmli UK: Cleavage of structural proteins during the assembly of the head of bacteriophage T4. Nature 227: 680-685, 1970. 